\title{
Hierarchy of Needs Theory and the Positive Psychology Construction of Chinese College Students
}

\author{
Yue Wu \\ Xi'an University of Technology, Xi'an, Shaanxi,710048,China \\ wuyue@xaut.edu.cn
}

\begin{abstract}
Keywords: Need hierarchy, College students, Positive psychology
Abstract: To a certain extent, Maslow's Hierarchy of Needs Theory is universal significance for people to build up positive psychology. During the course of cultivating the college student's positive psychological quality, the Hierarchy of Needs Theory can give guidance for the Chinese college students' positive emotional experience, positive psychological power of excavating, positive personality cultivating and long-lasting positive psychological effects.
\end{abstract}

\section{Introduction}

1.1 Introduction to the Hierarchy of Needs Theory. American psychologist Maslow (A.H.Maslow) proposed the Hierarchy of Needs Theory for the first time in his "A Theory of Human Motivation” (1943). Maslow explained the theory in 1954. He thought that all kinds of human needs can be roughly classified into five categories. The order of five kinds of needs from low to high is: physiological, security, belonging and love, self-esteem and self-actualization. For the fulfillment of human needs, Maslow believed that it is a process of gradual rise from low to high $^{[1]}$. Low-level needs are relatively easy to satisfy, and the high-lever needs are relatively difficult to satisfy. He had estimated that the five main needs from low to high satisfaction rate are: $85 \%, 70 \%, 50 \%, 40 \%$, and $10 \%{ }^{[1]}$. Maslow also believed that the needs of the people were dynamic and developing. People's behavior is subject to a variety of needs, but only one need is dominated every time. With the change of age, status and environment, the content of the needs will also change. The needs of the people as the growth of self development, the development of high-level needs does not make low-level needs disappear.

Later, after listening to some of doubts and questions Maslow also proposed the Transcendence Needs and the Deficiency Needs in "the theory Z". Deficiency needs which is formed on an organism formed by deficits need in essence. ${ }^{[2]}$ Only satisfying it, individuals can feel comfortable, but individuals often can only come from the external environment for things to enable to meet it, such as material, relationships or social status, etc. ${ }^{[3]}$. And Transcendence Needs is related to people's self-actualization. It is mainly for individual growth and development in order to achieve self-actualization. Transcendence Needs is of "peak experience", and the revelation of the universe, can be understood that beneficiary is not just a person, "individuals”, but is related to environment, and others.

In terms of utilization, Maslow believes the needs can arouse the enthusiasm of people, but there are two necessary conditions: one is that requirement have not get satisfaction. When some needs of the individual do not get satisfaction, so it will bring individual corresponding behavior; and the needs which are already satisfied cannot stimulate the vitality of the behavior. Secondly, before the individual's high-level needs are met, the lower level needs must be met. ${ }^{[1]}$

1.2 Realistic application of the Hierarchy of Needs Theory . Hierarchy of Needs Theory explains the inner link of all kinds of needs, and makes clear of the dominant role of people advantage needs and the method of gradually meet those needs, It not only provides better motivate people to work with support, also for a variety of incentive mechanism in management theory provide theoretical foundation. In addition, because this theory itself is simple and easy to understand the characteristics in every field of social management at home and abroad, it has been widely used. The practice proved this by empiricism and speculative philosophy theory of inductive indeed has certain application value in the field of social life. 


\section{Hierarchy of Needs Theory and the construction of Chinese college students' positive psychology}

The positive psychology is the most popular in recent years; the educators are exploring how to cultivate students by using positive psychology, to help students establish positive psychological quality. Positive psychology stressed that the cultivation of positive psychology has three themes: first, it is the positive emotional experience; the second, it is to excavate the potential positive strength; third, it is to cultivate positive personality. In fact, Maslow, as a humanism scholar, has always emphasized to study the psychology of ordinary people for letting these people live a better life. He built the Self-actualization Model Theory based on Hierarchy of Needs Theory which is the model of the study about positive personality traits. It is obvious that the Hierarchy of Needs Theory itself also has the same background. Need the psychological phenomenon is people's motivation, emotion and behavior is the essence of the people can have a positive subjective experience and, of course, is also the foundation of excitation potential positive force. Different needs of the development process, also is the people positive personality quality of the build process. So the Hierarchy of Needs Theory, to a certain extent, is common for people to build a positive psychological. Used in the field of education, of course it also can be positive for college student's psychological quality cultivation to give guidance.

2.1 Applying for the Hierarchy of Needs Theory, to explore the characteristics of Chinese college students' need satisfaction, for promoting positive emotion experience purposeful. A number of researches for the need status about Chinese college students show that the needs of the Chinese college students are rich and varied. Cheng-wei Liu (1997) when investigating Chinese college students found that "the college students themselves take example of the needs, which is more than 800 kinds" $^{[4]}$, induced, which is same to what Hierarchy of Needs Theory points out. Later a number of studies ${ }^{[6][7][8]}$ also show that the main need of Chinese college students is included in Maslow's need. In the aspect of advantage need, the researchers' report is not the same, but the most appears frequency about college students advantage need roughly are: survival needs, knowledge needs, friendship needs, communication needs, self-esteem needs, achievement needs, development needs, contribution needs, and so on. Seen from these studies, the need of Chinese college students about the high and low level needs is exist at the same time. But the high level needs are the leading roles. This is similar to Maslow's the paper about need of the development. So, we can explore the situation of Chinese college students' the need to be met according to the Hierarchy of Needs Theory for improving their positive emotion experience.

In modern university of China, advanced facilities, good living conditions and order, most of the college students' physiological and security needs can be met. But for part of the students whose family economic are difficulty, to meet their lower needs, to remove worries about the study and development, and to promote positive emotional experience, is the basic link of construct the positive psychology.

Due to the characteristics of cultural background and the growth stage, Chinese college students long for belonging and love. But it is not very mature in the expression of emotion and acceptance of it, and is slightly sensitive in the interactive, and at the same time the tolerance is not enough. If the needs do not considered in education, only emphasized on professional learning and ignored the emotion education, it will soon make the people that would be quasi-adults who are far from home bored, lost and other adverse psychological reaction. So, to help college students learn to express emotion and accept it, mutual interaction efficiency, and to help establish a good dormitory environment atmosphere, class, school ethos, and to increase the intimacy each other, the sense of belonging to the school, it is to promote their positive emotional experience, and the necessary link of building up the positive psychology.

Because of growing environment and the academic competition requirements, the self-esteem and competitiveness are relatively strong. Chinese college students always hope to get other people and social recognition, particularly value of self-identity. It is included in the content about the respect needs which Maslow stated. This need is not too easy to satisfy, but it is strong driving force. In terms of construction of positive psychology, respect them, often more reward less criticism, 
more understand empathy, respect their request, is to make students have a positive emotional experience, and is an important link of the positive behavior.

The development need is the most dominant need of Chinese college students. It is connected with the Maslow's self-actualization needs. The so-called development also is to realize their own value in social life in the future. Though, the satisfaction of the needs of the development is the result of the accumulation, but in college it is key point in the construction of positive psychology by seizing this advantage need to meet the requirements, and creating opportunities for their selfdevelopment, self-actualization and conditions, especially helping them understand the expectations of society, the State, and increasing the road of development for enhancing the positive emotion experience. It is the special link of building up the positive psychology.

2.2 According to the Hierarchy of Needs Theory, excavating the needs resources, for building up Chinese college students individual positive force. Because everyone is different in gender, age, personality, family background, the outlook on life, values, etc., individual need is different on the condition of the overall need consistent. The author survey more than 300 Chinese college students to found that the survival needs was the most important for grade four college students, but not for grade first college students. This requires educators actively focus on the characteristics of each student, in accordance with the Hierarchy of Needs Theory, exploring the needs and of different students, excavating related resources, for helping them meet requirements. This is the process of need to meet, and is the process of excavating their inherent advantage resources, building up positive psychology strength.

In addition, people's needs are complex and diverse; a person will often have multiple needs exist at the same time. Because the need hierarchy, function is different sometimes conflict between them, such as the lower-level needs and high-level needs, high level and high level needs will conflict between them. It is very easy to make childish students have psychological confusion. So, according to Maslow's instruction about different relationships, educators adjust the potential driving force behind these needs, forming a positive force, so as to help Chinese college students to deal with the relationship between the various needs. Also According to the need characteristics of Maslow stated, educators help students find their own advantage, and excavate the potential driving force behind these needs, and build up the individual positive mental force, eventually to promote the growth and development of college students.

2.3 According to development characteristics of needs status, forming campus atmosphere of positive psychology for helping Chinese college students cultivate positive personality quality. The influence of environment and atmosphere for people is favored, but the effect is very significant. It often can have influence on the level of individual personality. Maslow believes that people's needs will change with the environment changes. So, according to need development characteristic to build up a corresponding campus culture atmosphere, it also can help students build positive personality quality. Such as may, according to the characteristics of students' deficiency needs, educators can establish a warm, caring, optimistic, tolerant campus atmosphere actively, and can effectively help students build positive personality quality, compassion, the sense of responsibility. Again, for example, to establish and stimulate the campus cultural atmosphere relating to the self-actualization, educators can also help the students to form positive and optimistic positive personality quality.

Though Chinese college students need have individual differences, rules can still be found, For example many studies have shown that, Chinese college students who are in the same grade, the same sex, the same profession are similarity. So, educators also can be considered to establish the corresponding positive psychological micro-environment, such as building up a positive psychological community, school, grade, class, and even the dormitory atmosphere, educators try best to help every college students meet the needs and development needs, at the same time, achieve positive personality quality cultivation. Of course, educators also consider the various factors affecting environment and the characteristics of dynamic development about students, and adjust constantly developing environment for suiting for students. 
2.4 Helping Chinese college students build Transcendence Needs, for building up the longterm mechanism in the construction of positive psychology. With the development of the times, more and more people, especially Chinese college students begin to pay close attention to their own self-actualization. They often think that this is their own things, and has nothing to do with others. Some educators often teach them for catering to the needs which come from the growth of the students themselves and achievement to education, and do not mention society. To some extent, it may be a practical method. The word, self-actualization means, the achievement of self-worth, but how to reflect self-worth? Of course it is close to the development of society. The individual is much more emphasis on self-actualization or personal achievement, it is easy to cause personal development to disagree with the development of society, and hinds the self-actualization. Maslow saw the relationship between human needs and others, society relations, and put forward to the Transcendence Needs. He pointed out that this need not only was good for an individual, also good for others, society and the universe. During the course of education, if educators can help college students bring personal goals into correspondence with the expectations of society more, and guide them adaptive unity and unified regulatory to produce the Transcendence Needs. The students can achieve themselves better. It is beneficial and necessary for the students, nation and social development. As for the construction of positive psychology, the combination the personal selfactualization needs and the development of the society is basic measure of positive psychology long- lasting and stable. It is good news that the contribution need relating to the Transcendence Needs is exist in advantage need of the Chinese college students. So you can start to work from this need, and establish the transcendence needs, and try to deliver a meet the conditions forming a longterm mechanism of positive psychology.

Besides that, educators have to help college students realize that self-actualization needs or transcendence needs is the needs of the highest level in the Hierarchy of Needs Theory. So its implementation is also a step by step, and cannot jump to success. In reality, many college students make full use of every minute and work hard in order to achieve personal growth. But they harm their health for less material life and work and rest assurance. So, stimulating students have high needs, educators also must strengthen the reasonable need at the same time. Encouraging them effort to develop themselves, contributing to the society positively, and educators can build up a long-term mechanism in the construction of positive psychology in this way.

\section{Conclusion}

Although the Theory of Hierarchy of Needs in Chinese college students has great significance in the construction of positive psychology, but there are some problems should be paid attention to. First, as the western social psychologist Maslow, his theory is inevitable with individualistic, such as insufficient attention to the person's social attributes, and no further clarification on the relationship between the Transcendence Needs and society. Second, Maslow's Hierarchy of Needs is more inflexible, mechanization, and fails to consider cultural factors. Comparing with western students, Chinese college students has more collective consciousness, such as listed in the previous , the need of "contribution" is ubiquity in Chinese college students, and the Transcendence Needs which is mentioned by Maslow is only a few people which can achieve. Finally, under the background of China, "self-actualization" of Chinese college students is required to realized contribution and personal growth which is on the basis of the collective, the society, the State. This can be thought transcendence needs as dynamic role.

\section{References:}

[1] XuYan:personality psychology.BeiJing.Beijing Normal University Press.(2009).p.310-314

[2] Maslow:Maslow's humanistic philosophy.translated by ChengMing.BeiJing:JiuZhou Press,(2003).p.50

[3] XieLingzhi:Happiness and Transcendentalist. Journal of Chengdu University.Vol.22(2008).p.31 
[4] LiuChengwei:The cultivation of college students' psychological motivation and high level needs.Guangxi higher education research.vol.3. (1997)p.16

[5] CengBenjun:The structure research review about Chinese college students need. Journal of Chifeng university.vol32. (2011)p.233-234

[6] QInYongchao:College students' psychological need present situation investigation and research.Journal of Inner Mongolia university for nationalities.vol16. 2010).p.100

[7] LvHouchao ChangWen:The investigation of present situation of college students needs.Psychological Research..vol3. (2008).p. 87-92 